\title{
Internet assisted laboratories: design, educational use, and pedagogical evaluation
}

Lambertus Hesselink, Dharmarus Rizal, Eric Bjornson

Lambertus Hesselink, Dharmarus Rizal, Eric Bjornson, "Internet assisted laboratories: design, educational use, and pedagogical evaluation," Proc. SPIE 9663, Eighth International Topical Meeting on Education and Training in Optics and Photonics, 96630M (6 October 2003); doi: 10.1117/12.2208381

SDIE Event: Eighth International Topical Meeting on Education and Training in Optics and Photonics, 2003, Tucson, Arizona, United States 


\title{
Internet assisted laboratories: design, educational use, and pedagogical evaluation
}

\author{
Lambertus Hesselink, Dharmarus Rizal, and Eric Bjornson \\ Stanford University, Senvid, Inc., 420 Via Palou Mall, Stanford, California 94305-4075 \\ telephone: (415) 269-7102; e-mail:bert@kaos.stanford.edu
}

\begin{abstract}
We discuss the design considerations of Internet Assisted Laboratories (Ilabs), their educational use for teachers and students in the classroom and for homework, and the results of several pedagogical evaluations at Stanford University of remote optics Ilabs we have used since 1998.

(C)2003 Optical Society of America

OCIS codes: (180.2520) Fluorescence microscopy; (170.2520) Fluorescence microscopy
\end{abstract}

Internet-based learning extends beyond the confines of the classroom. Internet Assisted Laboratories (Ilabs) allow students and teachers access to experimental facilities from anywhere where there is an Internet connection. By controlling an actual experiment students can gain an understanding of and experience with physical phenomenon beyond that which the classroom offers. On-line experiments allow direct control of physical processes, observation of non-ideal phenomena such as noise and provide students with insight into practical limitations. By observing real physical processes under non-ideal conditions, students gain deeper physical intuition than textbooks and classroom lectures alone can offer.

\section{The Stanford Ilabs Study}

At Stanford University a pilot study was begun in 1997 with the following objectives: a) to develop a framework for integration of web-based classroom instruction and remote control of laboratory experiments; b) to implement a pilot program; c) to professionally and independently evaluate the performance and usefulness of the pilot program within the context of University learning; d) to explore new possibilities for improving classical classroom education. Since that early work, we have continued to innovate and develop new Ilabs technology and pedagogical tools. Although we have chosen optical experiments in this program, the concept of CyberLab lends itself for experimentation in almost any field, including but not limited to mechanical engineering, aeronautics, electrical engineering, physics, biology, chemistry, medicine, material science and earth sciences.

\section{Ilabs Designs and Implementations}

A functional web-based laboratory environment was created using novel Java-based technology specifically designed and implemented for Ilabs. The lab interface is designed with organization in mind that will teach good habits and etiquette. In addition to the remote control of physical experiments, the Ilabs interface also provides a lab scheduler, a reference library, course material, computer based analysis and simulation tools, testing facilities, and an electronic lab notebook. The Ilabs control software encrypts all transmissions, and allows control of equipment, even if it is located behind a firewall. New collaboration methods were developed allowing multiple users complete real-time access to data and experiments. Five optics laboratories have been implemented as well as a gas dynamics experiment, and a biology experiment using optical tweezers on nano-dimensions. A Stanford Ilabs showing optical diffraction is currently accessible at the OSA website www.optics4kids.org.

\section{Evaluation of CyberLab by the School of Education at Stanford University}

A "needs assessment" study was first conducted during October and November of 1998. Meetings and interviews with key participants, including the Principal Investigator and members of the CyberLab team were conducted in order to identify and outline the goals of the remote laboratory environment, to compose questions regarding the usability of CyberLab, and to identify potential problem areas of the program. The plan of action emphasized evaluation methods and instruments based on the data obtained from the needs assessment study. The primary methods and instruments chosen were surveys, observations, interviews, and the use of focus groups. The evaluation tools were designed to anonymously assess the goals of the program beginning with the pilot test in the 
Fall Quarter of 1998 and follow-on tests continued through the Spring Quarter of 1999. The pilot test was successful and a second study was initiated for the Spring Quarter of 2003.

In this invited presentation we discuss our latest results in all three above mentioned areas.

This research was partially supported by the Wallenberg Global Learning Network and Stanford University 